\title{
Changing Contents of Carbon Hybridizations in Amorphous Hydrogenated Carbon Layers (a-C:H) on Sustainable Polyhydroxybutyrate (PHB) Exhibit a Significant Deterioration in Stability, Depending on Thickness
}

\author{
Torben Schlebrowski ${ }^{1}$, Lucas Beucher ${ }^{1}$, Hadi Bazzi ${ }^{2}$, Barbara Hahn ${ }^{2}$, Stefan Wehner ${ }^{1}$ and \\ Christian B. Fischer $1,3, *,+(\mathbb{D}$ \\ 1 Department of Physics, University Koblenz-Landau, 56070 Koblenz, Germany \\ 2 Department of Material Analysis, RheinAhrCampus, University of Applied Sciences Koblenz, \\ 53424 Remagen, Germany \\ 3 Materials Science and Nano-Engineering Department, Mohammed VI Polytechnic University, \\ Ben Guerir 43150, Morocco \\ * Correspondence: chrbfischer@uni-koblenz.de; Tel.: +49-261-287-2345 \\ + Dedicated to Professor Stefan Wehner on the occasion of his 50th birthday.
}

Received: 2 August 2019; Accepted: 26 August 2019; Published: 30 August 2019

\begin{abstract}
PHB is a biodegradable polymer based on renewable raw materials that could replace synthetic polymers in many applications. A big advantage is the resulting reduction of the waste problem, as well as the conservation of fossil resources. To arrange it for various applications, the surface is arranged by plasma-enhanced chemical vapor deposition (PECVD) with amorphous hydrogenated carbon layers (a-C:H). Here, on a $50 \mu \mathrm{m}$ thick PHB-foil, a-C:H layers of different thicknesses $(0-500 \mathrm{~nm})$ were deposited in $50 \mathrm{~nm}$ steps. Surface topography was investigated by scanning electron microscopy (SEM), chemical composition by diffuse reflectance infrared Fourier transform (DRIFT) spectroscopy and wettability checked by contact angle. In addition, layers were examined by synchrotron supported X-ray photoelectron spectroscopy (XPS) and near edge X-ray absorption fine structure (NEXAFS), which revealed thickness dependent changes of the $\mathrm{sp}^{2} / \mathrm{sp}^{3}$ ratio. With increasing thickness, even the topography changes show internal, stress-induced phenomena. The results obtained provide a more detailed understanding of the predominantly inorganic a-C:H coatings on (bio)polymers via in situ growth.
\end{abstract}

Keywords: acetylene plasma; incremental a-C:H deposition; synchrotron based surface techniques; $\mathrm{sp}^{2} / \mathrm{sp}^{3}$ content evaluation; chemical environment survey; stress release phenomena

\section{Introduction}

A common feature of most polymers used in everyday life today is that they are based on crude oil. This inevitably causes a poor environmental impact, as these polymers are usually not (bio)degradable within a reasonable time. Due to the already high demand for plastics, which will increase rather than decrease, this will lead to a major disposal and raw material problem [1]. However, an adequate exchange of material is often not possible or appropriate, since polymers have some particularly advantageous properties: Formability, elasticity, low weight, wide working temperature range, chemical resistance and comparatively low cost [2,3]. Nevertheless, it needs to be mentioned that polymers cannot be used for every application, due to their poor mechanical properties, such as low hardness or insufficient resistance to surface abrasion [3]. This can be compensated by the deposition 
of protective coatings, such as amorphous hydrogenated carbon (a-C:H) layers. Additionally, the material can be specifically functionalized for particular applications [4-11]. As a result, the range of applications of many polymers can be greatly expanded. Conversely, this leads to a further increase in use and drives the disposal and raw material problems further forward [1]. One possible approach to solving the raw material situation is to change from classic crude oil-based polymers to those that can be obtained from renewable raw materials. If these are also biodegradable, the problem of disposal could also be solved. A promising candidate for this is polyhydroxybutyrate (PHB), which can be obtained from renewable resources by fermentation processes and is biodegradable [12]. Although this also shares the poor properties of polymers, it can be modified and adapted for special applications by depositing an a-C:H layer [5].

Those a-C:H films are mostly applied by chemical vapor deposition (CVD). The layer deposition can be further enhanced by the use of RF plasma (radio frequency plasma-enhanced chemical vapor deposition; RF-PECVD) [4,13-16], which can also be used for non-conductive materials at low temperatures $[5,13]$. The layers consist of hydrogen and $\operatorname{sp}^{2}(\sigma$ and $\pi)$, as well as $\mathrm{sp}^{3}$ hybridized interconnected carbons, where the $\mathrm{sp}^{2}$ clusters are limited to short chains embedded in an $\mathrm{sp}^{3}$ matrix of carbon and hydrogen $[4,17,18]$. The ratio of the carbon hybridizations, binding states and the hydrogen content can be controlled via the plasma parameter settings which determine the physical properties of the resulting layer $[4,17,18]$. If the deposited layer has a very high portion of $\mathrm{sp}^{3}$ bonds, it is similar to diamond and has a high hardness [13]. In contrast, a large amount of $\mathrm{sp}^{2}$ bonds leads to a more flexible, graphite-like layer with, e.g., electrical conductivity [13]. In addition, an influence of the existing bonding situation on the wettability of the surfaces is recognizable, which leads to a variation in contact angles [19].

The a-C:H coatings investigated in this study were applied to the biopolymer PHB by RF-PECVD using only acetylene plasma as the source for $\mathrm{C}$ and $\mathrm{H}$. The surface morphology of the layers was inspected ex situ by scanning electron microscopy (SEM); the chemical composition of the obtained coatings by diffuse reflectance infrared Fourier transform (DRIFT) spectroscopy and synchrotron-based X-ray techniques (near edge X-ray absorption fine structure (NEXAFS) and X-ray photoelectron spectroscopy (XPS)). In addition, contact angle measurements were performed to investigate surface wettability.

\section{Materials and Methods}

\subsection{Sample Preparation and Film Deposition}

The PHB foils were purchased at industrial quality from Goodfellow (Bad Nauheim, Germany) with the dimensions $30 \mathrm{~cm} \times 30 \mathrm{~cm}$. After delivery, the $50 \mu \mathrm{m}$ thick foils were cut to $10 \mathrm{~cm} \times$ $10 \mathrm{~cm}$ samples and mounted on self-made aluminum holders specially manufactured for the coating process. PECVD was chosen for the plasma treatment in a high-vacuum chamber. As plasma source, a RF-controlled (13.65 MHz) Copra DN 400 (Copra DN 400, CCR GmbH, Troisdorf, Germany) was used. The coating process is described in detail elsewhere $[5,20,21]$, but here only briefly: Sample holders were placed $275 \mathrm{~mm}$ in front of the plasma source. This direct alignment results in so-called r-type diamond-like carbon (DLC) coatings [20-23]. An initial oxygen plasma (10 min, $200 \mathrm{~W}, 1 \mathrm{~Pa}$, $65 \mathrm{sccm} / \mathrm{min}$ ) cleaned and activated the PHB surface for further coating. With subsequent exposure to acetylene plasma $\left(107 \mathrm{~W}, 0.65 \mathrm{~Pa}, 65 \mathrm{sccm} / \mathrm{min}\right.$, deposition rate ca. $\left.10 \mathrm{~nm} \cdot \mathrm{min}^{-1}\right)$, layer thicknesses of $0-500 \mathrm{~nm}$ in $50 \mathrm{~nm}$ steps were realized. Layer thicknesses above $500 \mathrm{~nm}$ were not feasible because the resulting layers were not stable, began to crack and then peeled off as the process progressed. This can be seen in the SEM section herein, as well as in previous work from our group [5]. In addition to the PHB samples, silicon wafers with partial cover by aluminum foil were placed on the holders to check the layer thicknesses obtained. The resulting layer edge could then be measured with a profilometer (Dektak 3, Veeco Instruments Inc., Plainview, NY, USA). 


\subsection{Analytical Techniques}

The surface morphologies of the plasma treated PHB samples were examined with a scanning electron microscope (SEM515, Phillips, $7 \mathrm{kV}$, WD $20 \mathrm{~mm}$ ). Since SEM investigations of polymers in particular are affected by charging effects caused by the electron beam, the samples were covered with a $7-10 \mathrm{~nm}$ thick conductive gold layer. In order to prove the accuracy of the investigations, measurements were carried out at least at three different points on each sample.

The surface wettability of the a-C:H layers was analyzed by a contact angle goniometer (OCA 15 plus, DataPhysics Instruments $\mathrm{GmbH}$, Filderstadt, Germany). For this purpose, $1 \mu \mathrm{L}$ drops of distilled water were applied to the samples in ambient conditions using the sessile drop technique. The resulting contact angles were measured and averaged at five different points of the entire sample to the left and right of each drop. This proves the homogeneity of the coating, ensures the accuracy of the values obtained and results in a representative value.

In order to obtain information about the chemical composition of the carbon atoms present in the a-C:H layers, infrared spectroscopic investigations were carried out. Due to the thin layers, DRIFT spectroscopy was chosen using a Shimadzu Fourier transform spectrometer (IRPrestige-21, Kyoto, Japan) equipped with the diffuse reflectance measuring apparatus DRS-8000 [24]. Measurements were performed at room temperature, under atmospheric pressure. Data was collected in two steps: First, a scan was performed over the entire spectral width (here $450-4000 \mathrm{~cm}^{-1}$ ) with a resolution of 4 wavenumbers. This was repeated 100 times and spectra were averaged to compensate statistical noise. This was necessary to evaluate graduations in which regions of the applied a-C:H layers showed changes, depending on the layer thickness. The second step was a detailed measurement of the so-called C-H stretching zone in the range of $2800-3100 \mathrm{~cm}^{-1}$ containing vibrations of the different C-bonds $[15,25]$. Here a resolution of one wavenumber was chosen and the measurements were repeated 300 times and averaged. Step two was repeated at three different points on the sample to prove homogeneity of the sample and to ensure accuracy. For both steps the $\mathrm{O}_{2}$ plasma treated PHB sample was used as reference, as each of the coated samples was first treated with an $\mathrm{O}_{2}$ plasma. The subsequent evaluation of the spectra was performed with the commercial IR Solution-FTIR Control Software (software version 1.30, Shimadzu Corporation, Kyoto, Japan): First, a multipoint baseline fit of the spectra, followed by a subsequent smoothing was done (note: this only changes the appearance but not the information or peak positions).

For a detailed analysis of the chemical environment, NEXAFS in combination with XPS was performed. The measurements were accomplished at the beamline HE-SGM at the synchrotron source BESSY II in Berlin during the low-alpha phase. The detection system is described in detail elsewhere [26]. An additionally installed flood-gun is used to compensate charging effects caused by the radiation that can influence the measurements.

NEXAFS-spectra were recorded for the C- and the O-edge. The C-edge was repeated at a second point to control homogeneity of the layer and to ensure correctness of the results. Subsequently, the spectra obtained were normalized with the commercial Origin software and adapted to the decreasing ring current of the low alpha phase. The background noise was also compensated and a contamination correction of the grid with a previously measured gold edge was performed. The individual steps are reported in detail by Watts et al. [27]. After spectrum smoothing all spectra were analyzed by a self-written peak evaluation program and obtained results were plotted with Origin software.

XPS was applied for supporting analysis and for quantitative determination of different sp-bonding states. First, a survey spectrum over the full width of $0-700 \mathrm{eV}$ was recorded for an overview of the elemental surface composition. For a more detailed analysis, both the $\mathrm{O} 1 \mathrm{~s}$ and the $\mathrm{C} 1 \mathrm{~s}$ peaks were recorded. The $\mathrm{C} 1 \mathrm{~s}$ peak was measured twice at different points to ensure homogeneity of the sample and measurement accuracy. The total C1s peak was analyzed with the commercial software CasaXPS to provide the proportions of $\mathrm{sp}^{2}, \mathrm{sp}^{3}$ and $\mathrm{C}-\mathrm{O}$ bonds. Using Origin software, the results were presented according to the layer thickness. 


\section{Results and Discussion}

\subsection{SEM Image Analysis}

Figure 1 shows representative SEM images for the different thicknesses of a-C:H layers on oxygen treated PHB samples. All images with increasing thickness starting with the $\mathrm{O}_{2}$ plasma treated one in Figure 1a display a sample section of $200 \mu \mathrm{m} \times 200 \mu \mathrm{m}$, except for the $500 \mathrm{~nm}$ deposition in Figure $1 \mathrm{k}$ (it is a $100 \mu \mathrm{m} \times 100 \mu \mathrm{m}$ detail).
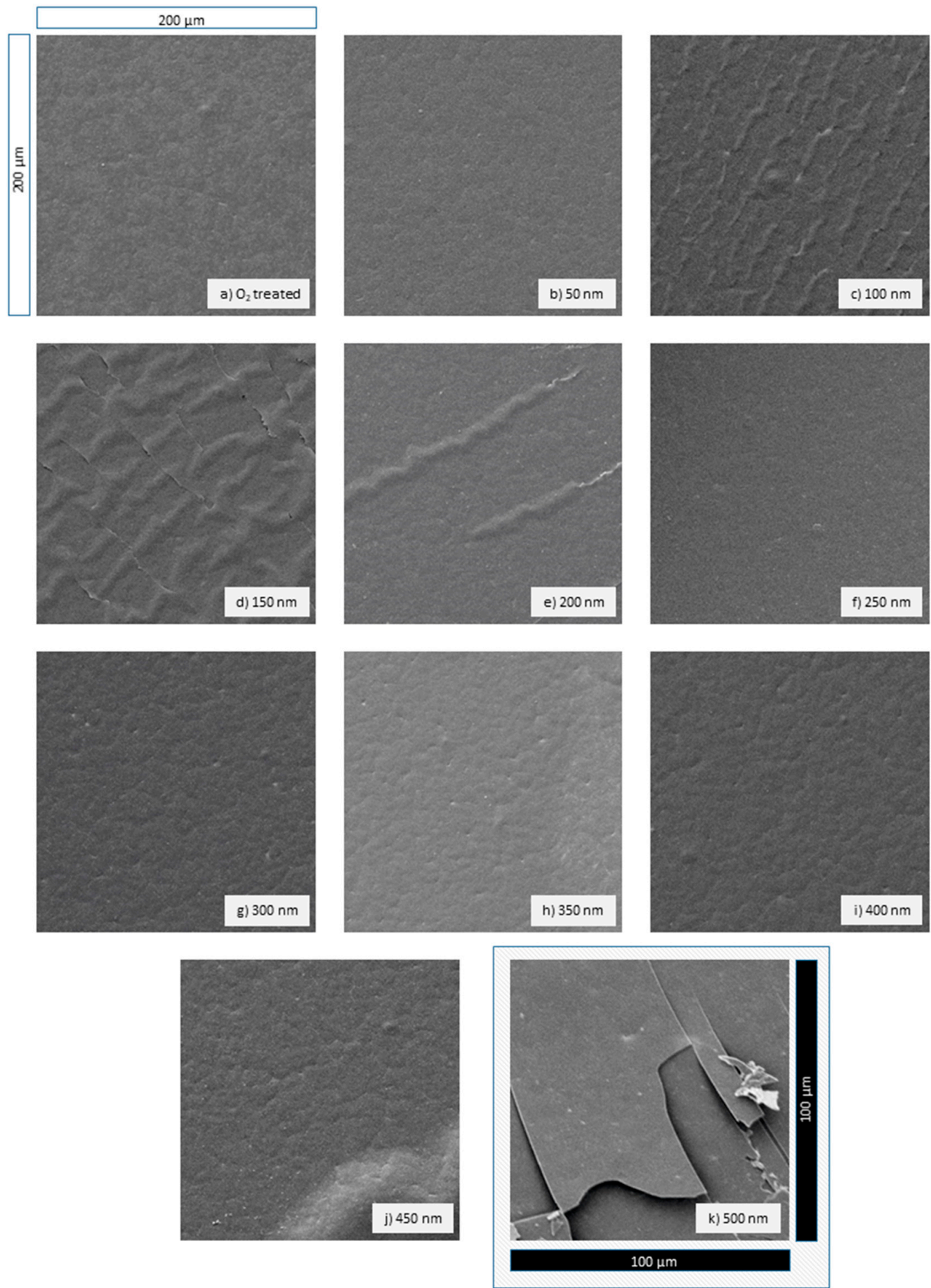

Figure 1. SEM images of PHB treated with $\mathrm{O}_{2}$ plasma (a) and coated with different thicknesses of a-C:H layers. The series (b-k) shows the changing topography of a-C:H coating increasing in $50 \mathrm{~nm}$ steps. 
Figure 1a shows PHB pretreated with $\mathrm{O}_{2}$ plasma. The surface appears roughened by the plasma treatment and dirt is removed. The SEM analysis revealed layer thicknesses of stable and unstable a-C:H coatings on PHB. In the case of thin films (50 nm, Figure 1b), a homogeneous, stable a-C:H film is formed. The previously observable roughness for the $\mathrm{O}_{2}$ plasma treated one (Figure 1a) decreases noticeably. With increasing layer thickness, the a-C:H film starts to delaminate and breaks open (100-200 nm, Figure 1c-e). First the carbon layer is still closed, but with strong visible crimps and ripples. This effect is called "telephone cord buckling" (and can be seen clearly in Figure 1d), indicating stress release phenomena [28,29]. At $200 \mathrm{~nm}$ (Figure 1e) the stress-related fractures in the carbon layer continue to increase. Afterwards a closed, homogeneous a-C:H layer is repeatedly formed on the PHB (250-400 nm, Figure 1f-i). Repeatedly, an emerging delamination is observable at a layer thickness of $450 \mathrm{~nm}$ (Figure 1j). With a layer thickness of $500 \mathrm{~nm}$ (Figure 1k), the deposited carbon film begins to tear open again and delaminate from the polymer.

The cracking and delamination of layers at 100-200 $\mathrm{nm}$ and $450-500 \mathrm{~nm}$ can be explained by internal stress. Reasons for this stress-related release are, e.g., different expansion coefficients of both materials (a-C:H layer and PHB substrate), as well as island formations of the a-C:H and their interaction with each other in the early growth stage [30]. The carbon layer on the material is stable until the stress exceeds a critical value and begins thereafter to delaminate. At first, the network can still hold the compound material together, but if the stress increases, the deposited layer begins to tear (Figure 1c-e,j,k).

\subsection{Surface Wettability by Contact Angles}

The surface wettability and the resulting contact angle depend in general, especially for the present a-C:H coatings, on several factors: The morphology of the surface [31-33], the existing chemical bonds [34-37] and different hybridization states of carbon on the surface [19,38,39]. The saturation of free bonds on the sample surface with hydrogen leads to the formation of strong $\mathrm{C}-\mathrm{H}$ bonds which in turn inhibit a possible interaction between the sample surface and the applied liquid, herein water $[34,36,37]$. Consequently, hydrogenation of the surface leads to a more hydrophobic behavior. On the other hand, if the surface is oxidized or contains oxygen groups, it is more attractive for water [35]. Likewise, different carbon hybridization states lead to a change in the contact angle behavior at the sample surface $[19,38,39]$. An $\mathrm{sp}^{3}$-rich surface has a reduced contact angle compared to a more $\mathrm{sp}^{2}$-rich $\mathrm{a}-\mathrm{C}: \mathrm{H}$ layer, because of the different free surface energy. The low polarity of its free bonds for $\mathrm{sp}^{2}$ hybridized carbon has a smaller surface energy compared to the covalent character of the $\mathrm{sp}^{3}$ bonded carbon $[13,19,40]$.

Figure 2 shows the contact angles obtained for the series of a-C:H layers of different thicknesses deposited on PHB. Additionally, the $\mathrm{O}_{2}$ plasma cleaned PHB sample is shown which was used as a reference. The contact angle range obtained is between $65^{\circ}$ and $80^{\circ}$. At $50 \mathrm{~nm}$ a- $\mathrm{C}: \mathrm{H}$, the lowest value of $66.5^{\circ}$ is found, indicating a more $\mathrm{sp}^{3}$ like hybridization of the carbon atoms. Furthermore, it shows a reduced content of oxygen-groups compared to the $\mathrm{O}_{2}$ plasma activated sample. With increasing layer thickness, the contact angle increases until it reaches a maximum of $79.7^{\circ}$ at $150 \mathrm{~nm}$. Since the overall deposition process compared to the $50 \mathrm{~nm}$ sample has not been changed except for a longer coating time to get thicker layers, the hybridization states have to change with increasing layer thickness; the proportion of $\mathrm{sp}^{2}$-hybridized carbon atoms increases. The contact angle measures also indicate surface roughening because of increasing error bars. At a layer thickness of $200 \mathrm{~nm}$, the contact angle drops rapidly down to $72.1^{\circ}$, accompanied by a large error. Here, the a-C:H layer was broken up, presumably due to stress within the layer (see also Figure 1e, SEM section). As the a-C:H thickness increases to $250 \mathrm{~nm}$ the contact angle value decreases slightly. At a carbon thickness of $300 \mathrm{~nm}$ the value rises up again to $79.3^{\circ}$. Further along, the contact angles decrease again and remain nearly constant with a slight decrease of the higher layers. 


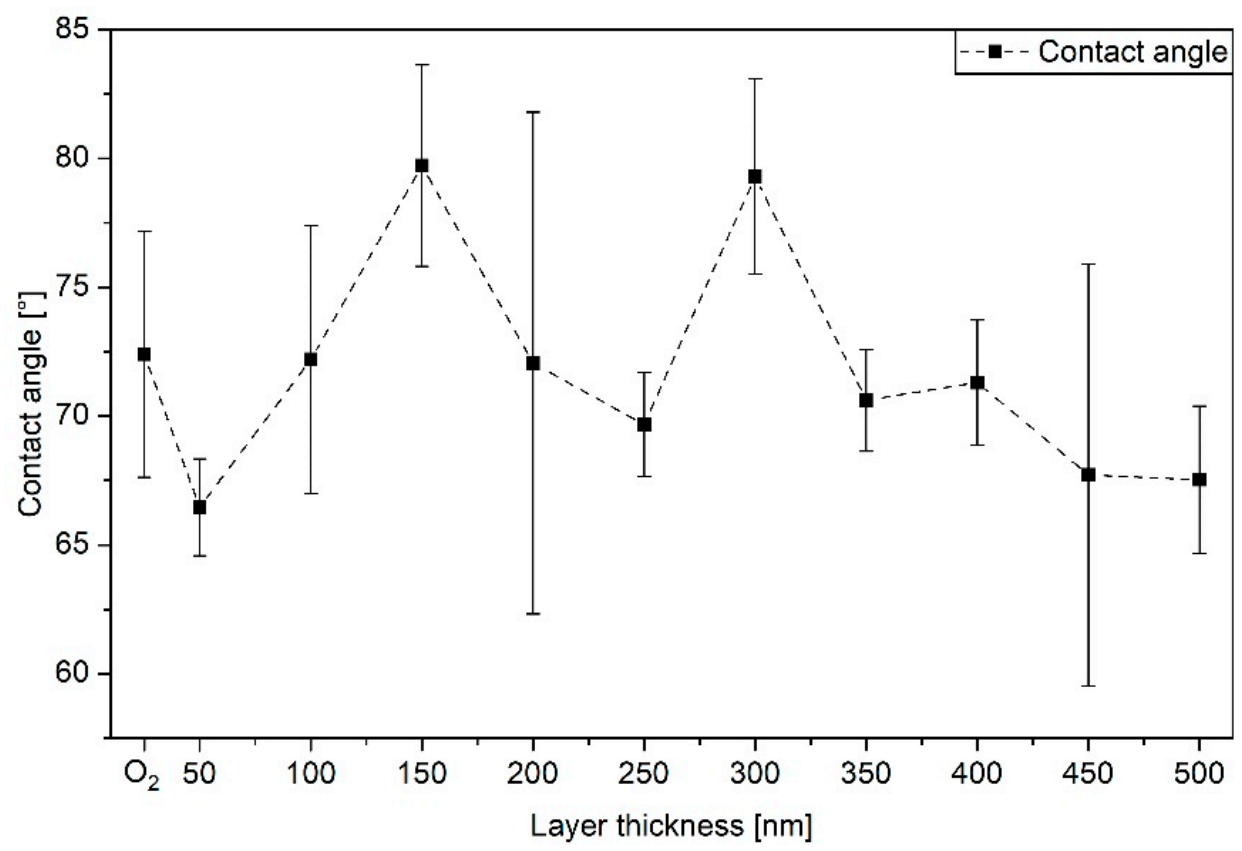

Figure 2. Contact angles of amorphous hydrogenated carbon $(\mathrm{a}-\mathrm{C}: \mathrm{H})$ coatings of various thickness on previously $\mathrm{O}_{2}$ plasma treated PHB samples (see first point). The dashed line is included to enhance visibility.

As lower contact angles indicate lower absolute $\mathrm{sp}^{2}$ contents; both the 150 and $300 \mathrm{~nm}$ depositions exhibit comparatively high values that deviate clearly from the behavior of the surrounding samples. These high contact angles are either due to a very high $\mathrm{sp}^{2}$ content, a strong hydrogenation of the surface or a change in the morphology. However, there is no evidence of such an increased proportion of $\mathrm{sp}^{2}$-hybridized carbon atoms in these layers in the following analytical techniques, so that morphological effects (starting the partially visible delamination of the carbon layer) are concluded here, which are supported by the large errors. Cracks in the layer are also responsible for fluctuating contact angles, at a thickness of 200 and at a thickness of $450 \mathrm{~nm}$ each. Since there is no longer a uniform surface, the contact angle measurements here are very error-prone, which is also indicated by the large error bars. It is noticeable that at the beginning of the coating and the "new coating" after the instable thickness at $150 \mathrm{~nm}$ is accompanied by an increase in the contact angle, which suggests a larger but somehow delayed $\mathrm{sp}^{2}$ content in the new, emerging layer.

\subsection{DRIFT Spectroscopy}

DRIFT spectroscopy was performed to examine the chemical composition and binding states of the PHB samples increasingly coated with a-C:H layers. First, the $\mathrm{O}_{2}$ plasma treated sample was compared with the crude PHB to investigate the chemical activation of the samples by the oxygen plasma pretreatment. Subsequently, detailed DRIFT measurements were performed for all a-C:H coated samples to investigate layer thickness dependent differences in the chemical composition of the a-C:H layers. For the coated samples, $\mathrm{O}_{2}$ plasma treated PHB was used as reference, since all carbon films were deposited on such pretreated PHB material. Figure 3 presents the corresponding spectra in ascending order plotted to arbitrary units (a.u.). The analysis of the DRIFT spectra was carried out on the basis of our own previous results, the work of other groups and known fundamental data $[15,23,25,41-43]$. In the range of 450 to $4100 \mathrm{~cm}^{-1}$ all samples were checked for chemical differences in the carbon coating first, before detailed analysis in the $\mathrm{C}-\mathrm{H}$ stretching area between $2750-3150 \mathrm{~cm}^{-1}$ for the $\mathrm{CH}_{2}$ and $\mathrm{CH}_{3}$ groups followed $[15,25,42,43]$. 


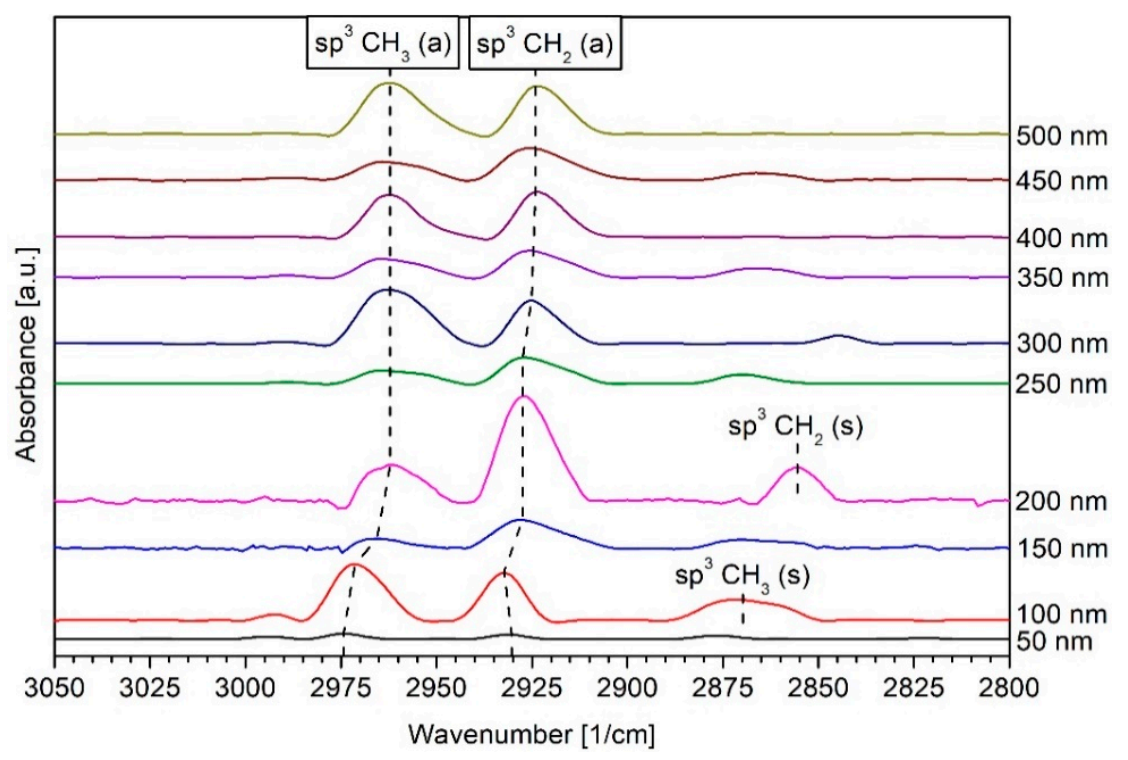

Figure 3. DIRFT spectra of the analyzed a-C:H layers with increasing thickness on PHB samples-substrate (indicated by changing colors with number labelling right next to it). The symmetrical (s) oscillations are only indicated for layer thicknesses with more pronounced intensity.

The formation of $\mathrm{CH}_{2}$ groups at relatively small a-C:H depositions are an established proof for an interlayer formation between the polymeric substrate and the carbon coating [41]. So-called subplantation processes are a reasonable explanation for this behavior, which consists of three main reactions: (i) Surface etching with plasma species, (ii) insertion of $\mathrm{C}$ and $\mathrm{H}+$ ions into the (sub)surface and (iii) surface absorption of plasma radicals to form new bonds. The interlayer formation stops at a layer thickness of around $50 \mathrm{~nm}$ and is considered complete as soon as the formation of $=\mathrm{CH}_{2}$ bonds takes place $[23,41]$. Therefore, a possible interlayer phase for the present PHB is less than $50 \mathrm{~nm}$. The $\mathrm{CH}_{2}$ groups reveal a more polymer-like DLC surface configuration, while the formation of $=\mathrm{CH}_{2}$ would indicate the $\mathrm{sp}^{2}$ carbon bonds in line to the cluster model [13]. For a detailed examination of the process, further investigations with layer thicknesses between 0 and $50 \mathrm{~nm}$ are necessary, but are not in the focus of this study.

The strong $\mathrm{sp}^{3}$ vibrations detected in the DRIFT spectra are also confirmed by XPS measurements (see later section). At $50 \mathrm{~nm}$ a-C:H, the $\mathrm{sp}^{3}$ bond is the dominant one. When measuring samples with a layer thickness of $100 \mathrm{~nm}$, these peaks are more pronounced. In addition, the dominant $\mathrm{sp}^{3} \mathrm{CH}_{3}$ asymmetric (a) peak at $2971 \mathrm{~cm}^{-1}$ widens towards $2950 \mathrm{~cm}^{-1}$ on its right flank. This can be explained by an overlay with the $\mathrm{sp}^{2} \mathrm{CH}_{2}$ symmetric (s) peak that is located at around $2950 \mathrm{~cm}^{-1}$ [42], which begins to form. Unfortunately, the two peaks could not be resolved separately, but the appearance of the $\mathrm{sp}^{2}$ vibration is in accordance with the XPS results (see later section). Additionally, a broad peak at $2870 \mathrm{~cm}^{-1}$ associated to the $\mathrm{sp}^{3} \mathrm{CH}_{3}$ (s) binding is visible [43]. At $150 \mathrm{~nm}$ a-C:H deposition, the formerly dominant $\mathrm{sp}^{3} \mathrm{CH}_{3}$ (a) peak shifts to $2965 \mathrm{~cm}^{-1}$ and almost disappears. The $\mathrm{sp}^{3} \mathrm{CH}_{3}$ (s) peak at $2870 \mathrm{~cm}^{-1}$ disappears nearly completely. The $\mathrm{sp}^{3} \mathrm{CH}_{2}$ (a) peak at a wavenumber of $2932 \mathrm{~cm}^{-1}$ shifts to a value of $2927 \mathrm{~cm}^{-1}$ and dominates the spectrum. This shift-back of the frequency indicates a smaller carbon-hydrogen binding energy, and therefore a higher carbon-hydrogen binding distance for the $\mathrm{CH}_{3}$ and $\mathrm{CH}_{2}$ group [25].

With an a-C:H layer thickness of $200 \mathrm{~nm}$, the $\mathrm{sp}^{3} \mathrm{CH}_{3}$ (a) peak is again more pronounced. On the other hand, a peak appears at $2855 \mathrm{~cm}^{-1}$, assigned to the $\mathrm{sp}^{3} \mathrm{CH}_{2}$ (s) binding [42,44-46]. The $\mathrm{sp}^{3} \mathrm{CH}_{2}$ (a) peak at $2927 \mathrm{~cm}^{-1}$ rises stronger and becomes the dominant one in the spectra. With $250 \mathrm{~nm}$ the spectrum changes again and is similar to the previous one for $150 \mathrm{~nm}$. The $\mathrm{sp}^{3} \mathrm{CH}_{2}$ (s) peak disappears and the $\mathrm{sp}^{3} \mathrm{CH}_{3}$ (a) one decreases again. Additionally, the $\mathrm{sp}^{3} \mathrm{CH}_{3}$ (s) peak at $2870 \mathrm{~cm}^{-1}$ appears again. The peak dominance is reversed by increasing the layer thickness to $300 \mathrm{~nm}$ a-C:H. The right flank, 
which has formed due to the superposition with the $\mathrm{sp}^{2} \mathrm{CH}_{2}$ (s) peak, is now falling more strongly, which is due to the fact that the $\mathrm{sp}^{2}$ oscillation becomes weaker. At a layer thickness of $350 \mathrm{~nm}$ the spectrum is similar to $150 \mathrm{~nm}$ and $250 \mathrm{~nm}$. With $400 \mathrm{~nm}$ of layer thickness, only two peaks are visible. Both the sp $\mathrm{CH}_{3}$ (a) peak at $2962 \mathrm{~cm}^{-1}$, still overlaid with the $\mathrm{sp}^{2} \mathrm{CH}_{2}$ (s) at $2950 \mathrm{~cm}^{-1}$ but nearly gone, and the $\mathrm{sp}^{3} \mathrm{CH}_{2}$ (a) at $2924 \mathrm{~cm}^{-1}$, are almost balanced. The spectrum for the $450 \mathrm{~nm}$ deposition is similar again to the ones of 150, 250 and $350 \mathrm{~nm}$. The $500 \mathrm{~nm}$ spectrum corresponds to the spectrum for $400 \mathrm{~nm}$ layer thickness.

The similarities in the DRIFT spectra for 50, 150 and $250 \mathrm{~nm}$ depositions indicate that with a layer thickness larger than $250 \mathrm{~nm}$ a new layer growth of the carbon coating begins after an earlier layer failure. Additionally, the similarities between the 200 and $300 \mathrm{~nm}$ layer thickness and for 150, 250 and $350 \mathrm{~nm}$ and their respective changes in the chemical environment suggest a layer thickness region that changes repeatedly in its chemistry between bonding networks.

\subsection{NEXAFS Results}

In Figure 4 the NEXAFS spectra for raw $\mathrm{PHB}$ and an $\mathrm{O}_{2}$ plasma treated one are shown. The spectra were processed as described in the experimental details. Both spectra do not differ significantly, except for a slightly higher intensity in the sample treated with $\mathrm{O}_{2}$ and small variations in the fingerprint region. The fact that $\mathrm{O}_{2}$ plasma-at least with respect to carbon bonds-has no changing properties, means it only serves herein to clean the sample surface of impurities. Based on the chemical structure of $\mathrm{PHB}$, the dominant peak is the $\mathrm{C}-\mathrm{C}$ bond.

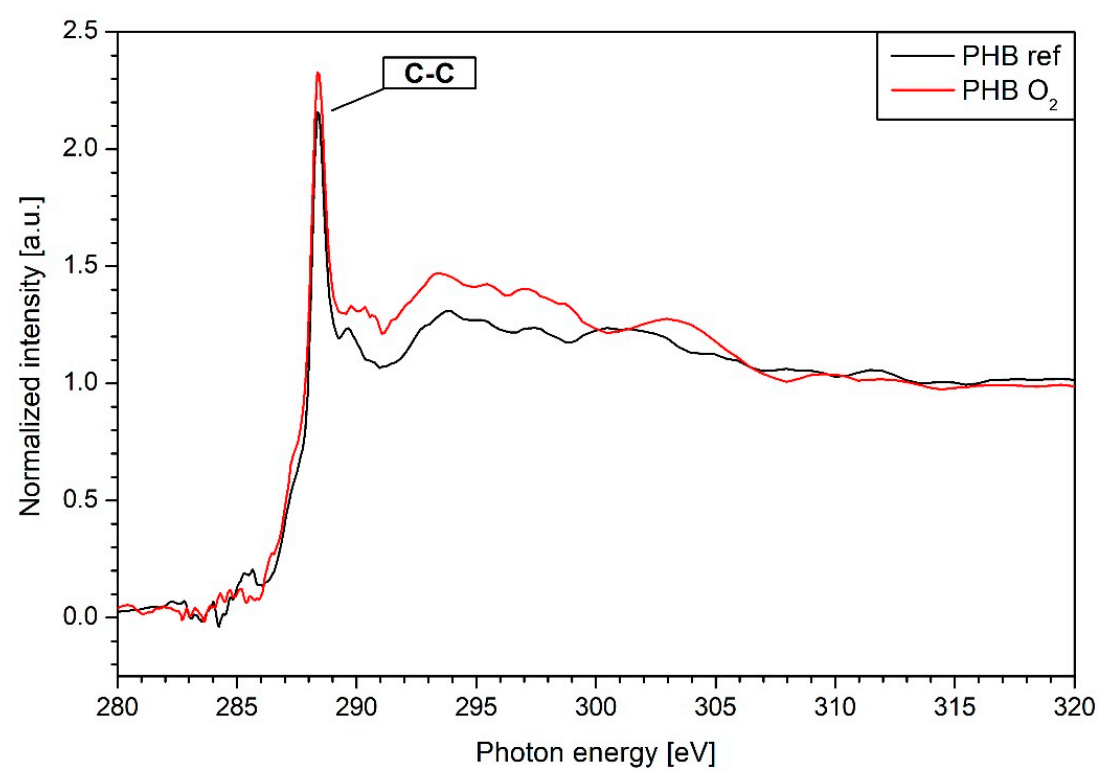

Figure 4. Near edge X-ray absorption fine structure (NEXAFS) spectra of a raw and untreated PHB (black) compared to an $\mathrm{O}_{2}$ plasma treated one (red), which is used as the new reference for further analysis.

The obtained NEXAFS spectra for the series of a-C:H layers with various thickness (here: 100, 200, 300, 400 and $500 \mathrm{~nm}$ ) are displayed in Figure 5 . The peak positions have been determined to $\mathrm{C}=\mathrm{C}$ $\pi(284.85 \mathrm{eV}), \mathrm{C} 002 \mathrm{DH}(286.15 \mathrm{eV}), \mathrm{C}-\mathrm{C}(288.35 \mathrm{eV})$ and $\mathrm{C}=\mathrm{C} \sigma(292.55 \mathrm{eV})$ [47-51]. The dominant binding resulting from NEXAFS studies is the $\mathrm{C}=\mathrm{C} \pi$ binding at an energy of $\sim 284.8 \mathrm{eV}$. For further analysis, all peaks for different binding states are normalized to the $\mathrm{C}=\mathrm{C} \pi$ peak and its ratio to the other peaks is analyzed. The ratio of $\mathrm{C}=\mathrm{C} \sigma$ to $\mathrm{C}=\mathrm{C} \pi$ bonds remains almost constant at all time. There is a deviation from this factor at a layer thickness of $100 \mathrm{~nm}$. Here, both the value of the ratio of $C-C$ to $\mathrm{C}=\mathrm{C} \pi$ and of $\mathrm{C}=\mathrm{C} \sigma$ to $\mathrm{C}=\mathrm{C} \pi$ make a jump, which can be attributed to a decrease in the proportion of 
$\mathrm{C}=\mathrm{C} \pi$. The ratio is here nearly $1: 1$ each. The ratio of the $\mathrm{C}-\mathrm{H}$ to $\mathrm{C}=\mathrm{C} \pi$ is almost constant over the entire variation of the a-C:H layer thickness.

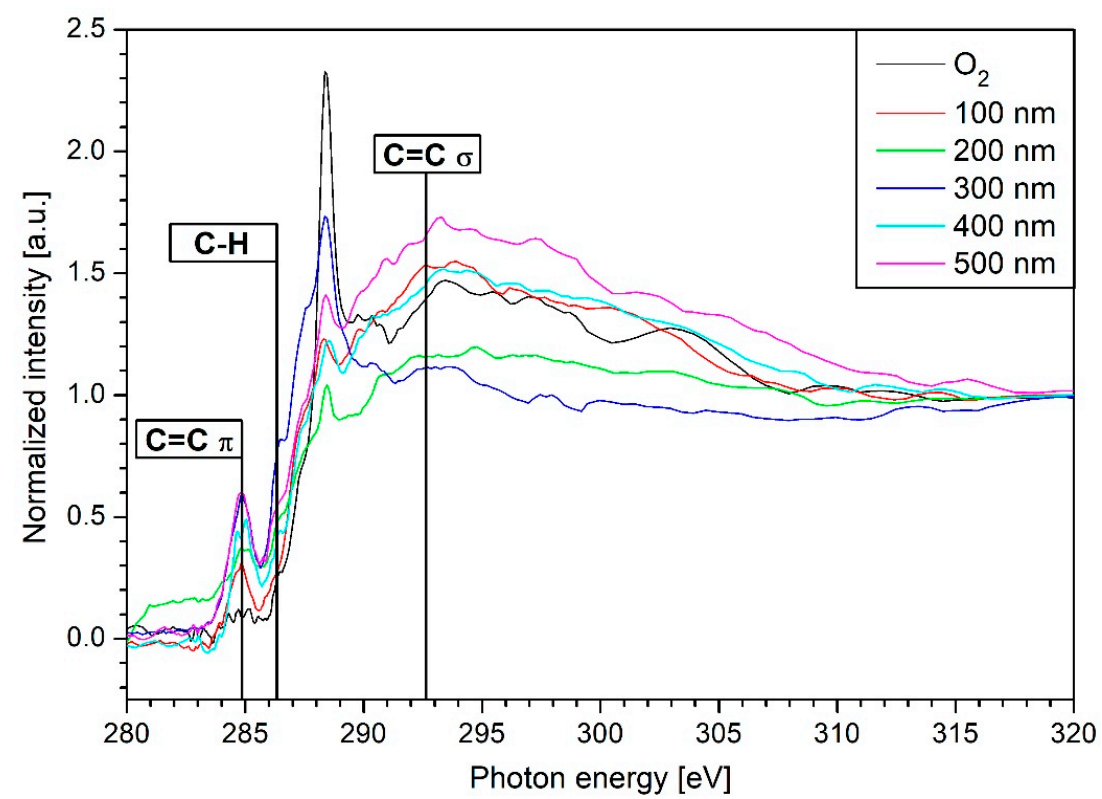

Figure 5. NEXAFS spectra of selected a-C:H layer thicknesses on PHB. Black is the reference sample, red a coating of $100 \mathrm{~nm}$, green $200 \mathrm{~nm}$, dark blue $300 \mathrm{~nm}$, pale blue $400 \mathrm{~nm}$ and magenta $500 \mathrm{~nm}$.

From a layer thickness of more than $400 \mathrm{~nm}$, a further deviation of the ratio occurs. From here the $\mathrm{C}=\mathrm{C} \pi$ bond increases steadily and the ratios of the three other bonds in relation to the $\mathrm{C}=\mathrm{C} \pi$ decrease further. Therefore, with a layer thickness of $100 \mathrm{~nm}$, the $\mathrm{sp}^{2}$ bond is the dominant one. This continues even at $200 \mathrm{~nm}$. With a layer thickness of $300 \mathrm{~nm}$ the $\mathrm{sp}^{3}$ peak begins to dominate. At $400 \mathrm{~nm}$, the $\mathrm{sp}^{2}$ value determined during NEXAFS measurements increases again and the $\mathrm{sp}^{3}$ content decreases. At $500 \mathrm{~nm}$, the values measured for $\mathrm{sp}^{2}$ are again the dominant ones.

The dominant $\mathrm{sp}^{2}$ bond between 100 and $200 \mathrm{~nm}$ corresponds to the "cord buckling" visible in the SEM images. As the dominance of the $\mathrm{sp}^{2}$ bonds increases from 100 to $200 \mathrm{~nm}$, the deterioration of the a-C:H layers intensifies according to the SEM images. With the change from the $\mathrm{sp}^{2}$ bond to the now stronger $\mathrm{sp}^{3}$ bond, that effect disappears, and the layer seems homogeneous again. After repeated decrease of the dominance of the $\mathrm{sp}^{3}$ bond and an increasing sp $\mathrm{sp}^{2}$ content between 400 and $500 \mathrm{~nm}$ again, "cord buckling" and layer failure occurs. The NEXAFS data therefore indicates a layer failure or layer defect if the $\mathrm{sp}^{3}$ bond loses its dominant position in favor of the $\mathrm{sp}^{2}$ bond. The results found here are in line with the following XPS results.

\subsection{XPS Results}

Figure 6 shows the results of the XPS measurements for PHB raw, $\mathrm{O}_{2}$ plasma treated and coated with $50 \mathrm{~nm}$ a-C:H. The analysis has been arranged according to the experimental details. The peak positions have been determined through the NIST database and work of other groups [52-54]. Contrary to the expectations, the $\mathrm{O}_{2}$ plasma treatment on $\mathrm{PHB}$ decreases the O1s peak (532 eV) compared to the untreated sample. This may be due to degradation or removal of the carbonyl group in PHB, resulting in a dangling bond, and therefore a free carbon position. The $\mathrm{C} 1 \mathrm{~s}$ peak $(284 \mathrm{eV})$ also changes and shows a more pronounced and sharper shape after the $\mathrm{O}_{2}$ plasma treatment. The widening of the $\mathrm{C} 1 \mathrm{~s}$ peak to higher binding energies indicates additionally, the appearance of $\mathrm{C}-\mathrm{O}$ binding. Applying the a-C:H layer changes the spectrum again. The O1s bonds are covered with an a-C:H layer and disappeared in the XPS survey. A shape change of the $\mathrm{C} 1$ s peak compared to the raw and $\mathrm{O}_{2}$ plasma treated sample is visible. 


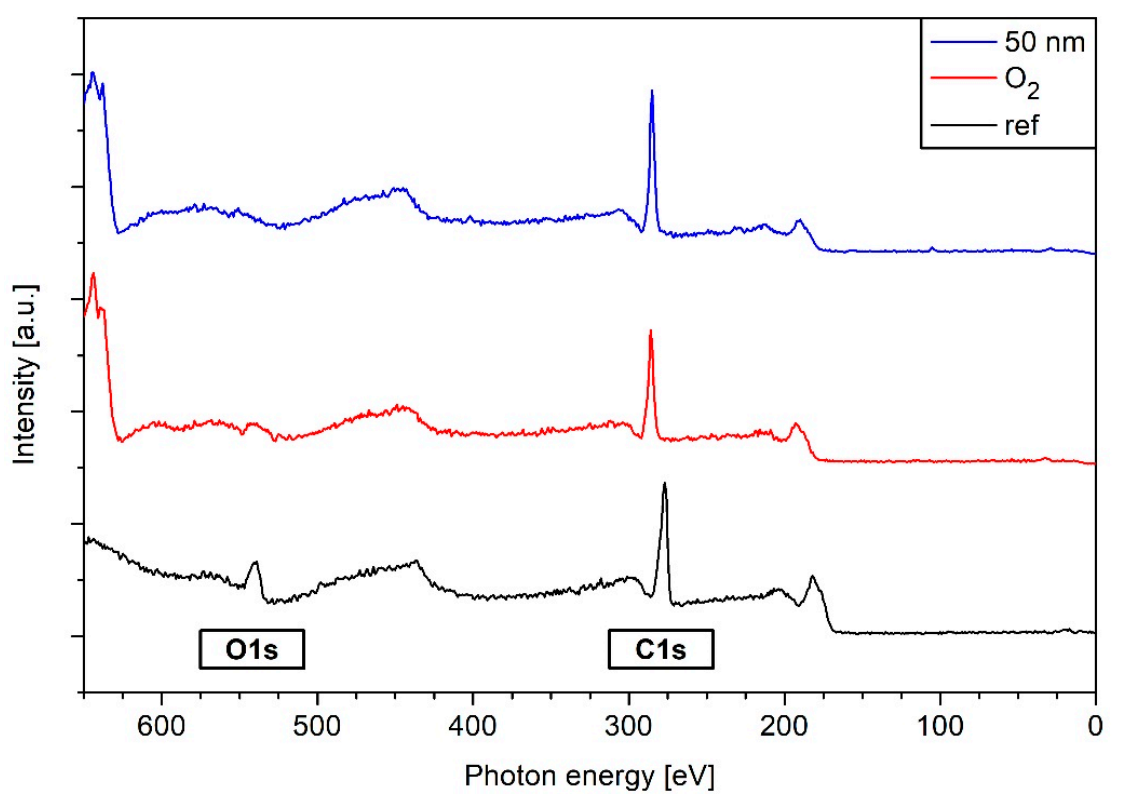

Figure 6. Full X-ray photoelectron spectroscopy (XPS) spectra of raw, $\mathrm{O}_{2}$ treated and with a $50 \mathrm{~nm}$ a-C:H layer coated PHB. The disappearance for the $\mathrm{O} 1 \mathrm{~s}(532 \mathrm{eV})$ and shape changes in $\mathrm{C} 1 \mathrm{~s}(284 \mathrm{eV})$ are clearly visible.

Figure 7 shows the evaluated percentages for $\mathrm{sp}^{2}$ and $\mathrm{sp}^{3}$ binding of the $\mathrm{C} 1 \mathrm{~s}$ peak as a function of the increasing layer thickness. In the Supporting Information, the deconvolution of selected C1s peaks together with all obtained values can be found. At $50 \mathrm{~nm}$ the $\mathrm{sp}^{3}$ bond is dominant, which is in accordance with the DRIFT results. With a layer thickness of $100 \mathrm{~nm}$, this dominance changes in favor of the $\mathrm{sp}^{2}$ bond. This remains the preferred bond type in the network until the layer thickness exceeds $200 \mathrm{~nm}$. Both the DRIFT and the NEXAFS measurements confirmed this behavior of a growing $\mathrm{sp}^{2}$ content. Thereafter, the situation changes again from the $250 \mathrm{~nm}$ a-C:H deposition and the sp ${ }^{3}$ binding is repeatedly the favored one. As soon as the layer thickness exceeds $400 \mathrm{~nm}$, there is another switch and the $\mathrm{sp}^{2}$ bond is the preferred one in the network, which is in line to the findings confirmed by DRIFT and NEXAFS results.

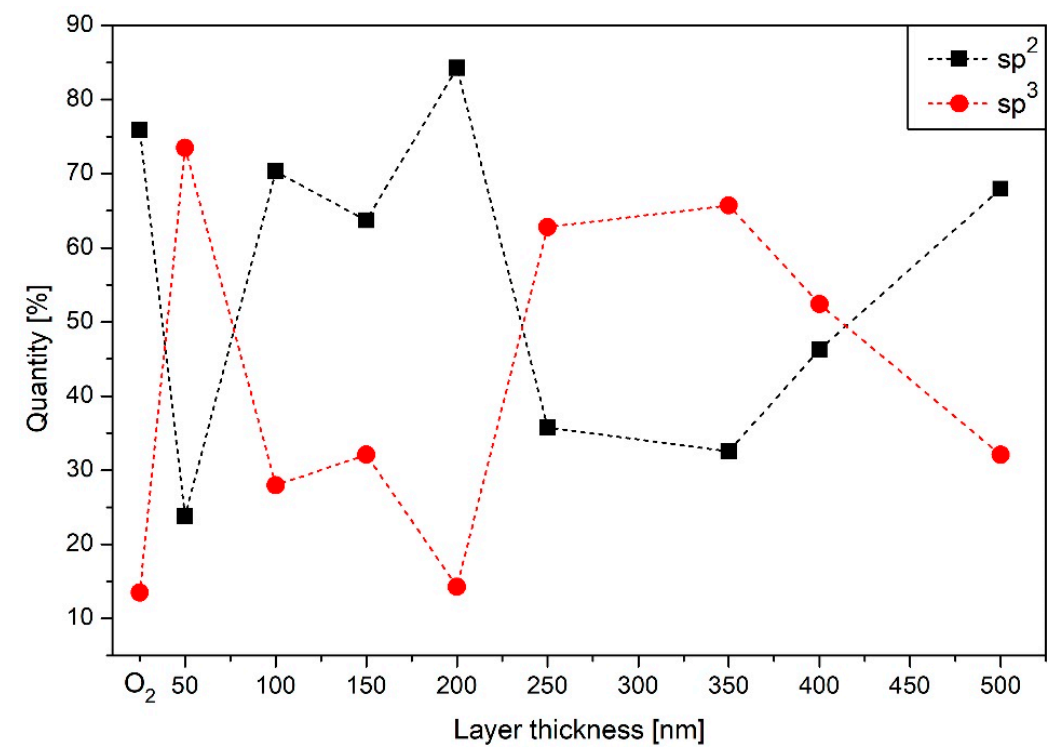

Figure 7. Results for the $\mathrm{sp}^{2}$ (squares) and $\mathrm{sp}^{3}$ (circles) from the XPS series for PHB coated with increasingly thick a-C:H layers. The dashed lines are included to enhance visibility. 
The $500 \mathrm{~nm}$ XPS measurement is in contradiction to the DRIFT measurements. XPS shows a strong $\mathrm{sp}^{2}$ content while the DRIFT results indicate dominant $\mathrm{sp}^{3}$ binding. The XPS data is supported by the NEXAFS results which also show dominant $\mathrm{sp}^{2}$ binding. A reason for the contradictory results of XPS/NEXAFS and DRIFT may be the different penetration depths of the techniques (a few nm compared to 10-20 nm, respectively). In addition, the sample surface is cracked or rather delaminated at $500 \mathrm{~nm}$, which certainly influences the results.

It is noticeable that the change from $\mathrm{sp}^{3}$ to $\mathrm{sp}^{2}$ as the dominant bonding is accompanied by a delayed breakup of the layer from 100 to $150 \mathrm{~nm}$ (see Section 3.1 SEM Image Analysis). A shift from $\mathrm{sp}^{2}$ to $\mathrm{sp}^{3}$ as the dominant binding, in contrast, seems to have no effect on the stability of the applied $\mathrm{a}-\mathrm{C}: \mathrm{H}$ layer on the PHB substrate. This is in accordance with results obtained for a-C:H layers on the biopolymer polylactide acid (PLA) [55], although PLA did not show any delay in layer failure. Furthermore, the comparison of SEM images with XPS shows that a $\mathrm{sp}^{2}$ dominated a-C:H layer on PHB is accompanied by "cord buckling" phenomena.

\section{Conclusions}

Layers of different a-C:H thicknesses were deposited on the biopolymer PHB using an acetylene plasma. The samples were analyzed with SEM, contact angle measurements, DRIFT spectroscopy, NEXAFS and XPS. Stable a-C:H layers on the examined PHB samples could be identified by SEM. Exceptions are the layers between 100 and $200 \mathrm{~nm}$ and thicknesses higher than $450 \mathrm{~nm}$. This is in line to the highly fluctuating contact angles and their corresponding error bars. Not only the DRIFT investigation, but also both the NEXAFS and the XPS measurements, revealed a changing chemical composition of the layer with increasing thickness. In the beginning the $\mathrm{sp}^{2}$ content increases as the layer thickens in accordance to the contact angles. In the DRIFT investigations also, a shift for the $=\mathrm{CH}_{2}$ group was found, which indicates a changing binding distance and confirms a changing chemical environment in the presented layers. Furthermore, the DRIFT measurements showed that if there is an interlayer between the polymer and a-C:H layer, it is already completed before or by the $50 \mathrm{~nm}$ layer thickness. For a better understanding of the deposition process of a-C:H layers on PHB, this interlayer formation and its thickness needs to be analyzed, which is currently under investigation.

The results obtained with the current analytical techniques are largely consistent and present a nearly identical picture of the growth behavior of the a-C:H layers on PHB. Smaller deviations are caused, on the one hand by the different penetration depths of the measurement techniques, and on the other hand, by the stress-induced damaged surface. It has to be emphasized that a shift from $\mathrm{sp}^{3}$ to $\mathrm{sp}^{2}$ as the dominant carbon binding leads to a layer failure proven by SEM measurements due to stress release. This also corresponds to recent results for a-C:H layers on the biopolymer film polylactide acid (PLA). But in contrast to PLA, the layer failure for the presented a-C:H on PHB has a delay of roughly $100 \mathrm{~nm}$ film thickness, after the change from $\mathrm{sp}^{3}$ to $\mathrm{sp}^{2}$ as the dominant binding type. This occurs repeatedly after the turnaround at 100 and $400 \mathrm{~nm}$.

The bonding ratios of the carbon atoms and the chemical environment depend not only on the applied plasma parameters, but also on the resulting a-C:H layer thickness. This means, similarly to recent results in our group for the biopolymer PLA, layers can also be customized for specific applications by checking the layer thickness of a-C:H on the present PHB. In summary, it is possible to deposit stable a-C:H layers with specific properties on the biopolymer PHB for most layer thicknesses up to $450 \mathrm{~nm}$. A thickness dependent change between the $\mathrm{sp}^{3}$ or $\mathrm{sp}^{2}$ dominant carbon species in the present a-C:H coating process on $\mathrm{PHB}$ has been proven with various methods.

Author Contributions: Both T.S. and C.B.F. conceptualized the study and developed the related methodology. T.S. prepared the samples and performed the data evaluation, visualization and wrote the original draft. T.S. and C.B.F. reviewed and edited the manuscript. L.B. contributed in terms of contact angle acquisition. SEM related analyses were performed by H.B. and B.H. NEXAFS, XPS and DRIFT acquisition and evaluation was conducted by T.S. Both authors S.W. and C.B.F. contributed in terms of funding acquisition, project management, supervision and overall guidance in the study. 
Funding: Funding for this work was provided by the German Research Foundation DFG (Deutsche Forschungsgemeinschaft) through the projects WE 4100/23-1 and FI 1802/14-1. T.S. and C.B.F. thankfully acknowledge the financial support by HZB.

Acknowledgments: The authors thank Heinz Busch (NTTF Coatings GmbH, Rheinbreitbach, Germany) for the industrial coating of the samples, and Joachim Scholz and Michael Kunze for the DRIFT equipment. The authors acknowledge the scientific collaborations between the Department of Physics of the University of Koblenz-Landau, and the Department of Chemistry of the University of Koblenz-Landau. The authors also want to thank Alexei Nefedov from KIT (Karlsruhe Institute for Technology, Group: Chemistry of oxidic and organic interfaces; X-ray and Electron Spectroscopy at Interfaces) for beamtime support. We thank the Helmholtz-Zentrum Berlin (HZB) for the allocation of synchrotron radiation.

Conflicts of Interest: The authors declare no conflict of interest.

\section{References}

1. Ryan, P.G. Brief History of Marine Litter Research. In Book Marine Anthropogenic Litter; Bergmann, M., Gutow, L., Klages, M.A., Eds.; Springer International Publishing: Cham, Germany, 2015; pp. 1-25.

2. Andrady, A.L.; Neal, M.A. Applications and societal benefits of plastics. Philos. Trans. R. Soc. B Biol. Sci. 2009, 364, 1977-1984. [CrossRef]

3. Sabbatini, L. Polymer Surface Characterization; De Gruyter: Berlin, Germany; Boston, MA, USA, 2014; ISBN 978-3110275087.

4. Grill, A. Plasma-deposited diamondlike carbon and related materials. IBM J. Res. Dev. 1999, 43, 147-162. [CrossRef]

5. Rohrbeck, M.; Körsten, S.; Fischer, C.B.; Wehner, S.; Kessler, B. Diamond-like carbon coating of a pure bioplastic foil. Thin Solid Film. 2013, 545, 558-563. [CrossRef]

6. Rohrbeck, M.; Fischer, C.; Wehner, S.; Meier, J.; Manz, W. DLC-coated pure bioplastic foil. Vákuum Forsch. Und Prax. 2014, 26, 42-47. [CrossRef]

7. Schink, C.; Catena, A.; Heintz, K.; Görls, H.; Beresko, C.; Ankerhold, G.; von der Au, M.; Meermann, B.; Van Malderen, S.J.M.; Vanhaecke, F.; et al. Attaching photochemically active ruthenium polypyridyl complex units to amorphous hydrogenated carbon (a-C:H) layers. Adv. Mater. Interfaces 2019, 6, 1801308. [CrossRef]

8. Bito, K.; Hasebe, T.; Maegawa, S.; Kitagawa, T.; Matsumoto, T.; Suzuki, T.; Hotta, A. Micropatterning of a 2-methacryloyloxyethyl phosphorylcholine polymer surface by hydrogenated amorphous carbon thin films for endothelialization and antithrombogenicity. Acta Biomater. 2019, 87, 187-196. [CrossRef] [PubMed]

9. Dufils, J.; Faverjon, F.; Héau, C.; Donnet, C.; Benayoun, S.; Valette, S. Evaluation of a variety of a-C:H coatings on PEEK for biomedical implants. Surf. Coat. Technol. 2017, 313, 96-106. [CrossRef]

10. Ishikawa, T.; Choi, J. The effect of microstructure on the tribological properties of a-C:H films. Diam. Relat. Mater. 2018, 89, 94-100. [CrossRef]

11. Ray, S.C.; Mukherjee, D.; Sarma, S.; Bhattacharya, G.; Mathur, A.; Roy, S.; McLaughlin, J. Functional diamond like carbon (DLC) coatings on polymer for improved gas barrier performance. Diam. Relat. Mater. 2017, 80, 59-63. [CrossRef]

12. Ahn, W.S.; Park, S.J.; Lee, S.Y. Production of Poly(3-Hydroxybutyrate) by Fed-Batch Culture of Recombinant Escherichia coli with a Highly Concentrated Whey Solution. Appl. Environ. Microbiol. 2000, 66, 3624-3627. [CrossRef]

13. Robertson, J. Diamond-like amorphous carbon. Mater. Sci. Eng. R Rep. 2002, 37, 129-281. [CrossRef]

14. Robertson, J. Plasma Deposition of Diamond-Like Carbon. Jpn. J. Appl. Phys. 2011, 50, 01AF01-1-01AF01-8. [CrossRef]

15. Koidl, P.; Wild, C.; Dischler, B.; Wagner, J.; Ramsteiner, M. Plasma Deposition, Properties and Structure of Amorphous Hydrogenated Carbon Films. Mater. Sci. Forum. 1990, 52, 41-70. [CrossRef]

16. Aldeeb, M.A.; Morgan, N.; Abouelsayed, A.; Amin, K.M.; Hassaballa, S.; Hassablla, S. Correlation of acetylene plasma discharge environment and the optical and electronic properties of the hydrogenated amorphous carbon films. Diam. Relat. Mater. 2019, 96, 74-84. [CrossRef]

17. Grill, A. Diamond-like carbon coatings as biocompatible materials-An overview. Diam. Relat. Mater. 2003, 12, 166-170. [CrossRef]

18. Couderc, P.; Catherine, Y. Structure and physical properties of plasma-grown amorphous hydrogenated carbon films. Thin Solid Film. 1987, 146, 93-107. [CrossRef] 
19. Paul, R.; Das, S.N.; Dalui, S.; Gayen, R.N.; Roy, R.K.; Bhar, R.; Pal, A.K.; Das, S. Synthesis of DLC films with different $\mathrm{sp}^{2} / \mathrm{sp}^{3}$ ratios and their hydrophobic behaviour. J. Phys. D Appl. Phys. 2008, 41, 1-7. [CrossRef]

20. Fischer, C.B.; Rohrbeck, M.; Wehner, S.; Richter, M.; Schmeißer, D. Interlayer formation of diamond-like carbon coatings on industrial polyethylene. Appl. Surf. Sci. 2013, 271, 381-389. [CrossRef]

21. Catena, A.; McJunkin, T.; Agnello, S.; Gelardi, F.M.; Wehner, S.; Fischer, C.B. Surface morphology and grain analysis of successively industrially grown amorphous hydrogenated carbon films (a-C:H) on silicon. Appl. Surf. Sci. 2015, 347, 657-667. [CrossRef]

22. Catena, A.; Agnello, S.; Rösken, L.M.; Bergen, H.; Recktenwald, E.; Bernsmann, F.; Busch, H.; Cannas, M.; Gelardi, F.M.; Hahn, B.; et al. Characteristics of industrially manufactured amorphous hydrogenated carbon (a-C:H) depositions on high-density polyethylene. Carbon 2016, 96, 661-671. [CrossRef]

23. Catena, A.; Kunze, M.R.; Agnello, S.; Gelardi, F.M.; Wehner, S.; Fischer, C.B. Amorphous hydrogenated carbon (a-C:H) depositions on polyoxymethylene: Substrate influence on the characteristics of the developing coatings. Surf. Coat. Technol. 2016, 307, 658-665. [CrossRef]

24. Armaroli, T.; Bécue, T.; Gautier, S. Diffuse Reflection Infrared Spectroscopy (Drifts). Oil Gas Sci. Technol. 2004, 59, 215-237. [CrossRef]

25. Günzler, H.; Gremlich, H.U. IR Spectroscopy: An Introduction; Wiley-VCH: Weinheim, Germany, 2002.

26. Nefedov, A.; Wöll, C. Advanced Applications of NEXAFS Spectroscopy for Functionalized Surfaces. In Book Surface Science Techniques; Bracco, G., Holst, B., Eds.; Springer: Berlin/Heidelberg, Germany, 2013; pp. 277-303.

27. Watts, B.; Thomsen, L.; Dastoor, P.C. Methods in carbon K-edge NEXAFS: Experiment and Analysis. J. Chem. Phys. 2014, 140, 105-120. [CrossRef]

28. Mei, H.; Huang, R.; Chung, J.Y.; Stafford, C.M.; Yu, H.H. Buckling modes of elastic thin films on elastic substrates. Appl. Phys. Lett. 2007, 90, 151902. [CrossRef]

29. Volinsky, A.A. Experiments with in-situ thin film telephone cord buckling delamination propagation. MRS Proc. 2002, 749. [CrossRef]

30. Davis, C.A. A simple model for the formation of compressive stress in thin films by ion bombardment. Thin Solid Film. 1993, 226, 30-34. [CrossRef]

31. Banerjee, D.; Mukherjee, S.; Chattopadhyay, K. Controlling the surface topology and hence the hydrophobicity of amorphous carbon thin films. Carbon 2010, 48, 1025-1031. [CrossRef]

32. Feng, L.; Li, S.; Li, Y.; Li, H.; Zhang, L.; Zhai, J.; Song, Y.; Liu, B.; Jiang, L.; Zhu, D. Super-Hydrophobic Surfaces. Adv. Mater. 2002, 14, 1857-1860. [CrossRef]

33. Barthlott, W.; Neinhuis, C. Purity of the sacred lotus, or escape from contamination in biological surfaces. Planta 1997, 202, 1-8. [CrossRef]

34. Piazza, F.; Morell, G. Wettability of hydrogenated tetrahedral amorphous carbon. Diam. Relat. Mater. 2009, 18, 43-50. [CrossRef]

35. Tay, B.K.; Sheeja, D.; Lau, S.P.; Guo, J. Study of surface energy of tetrahedral amorphous carbon films modified in various gas plasma. Diam. Relat. Mater. 2003, 12, 2072-2076. [CrossRef]

36. Ostrovskaya, L.; Perevertailo, V.; Ralchenko, V.; Dementjev, A.; Loginova, O. Wettability and surface energy of oxidized and hydrogen plasma-treated diamond films. Diam. Relat. Mater. 2002, 11, 845-850. [CrossRef]

37. Ostrovskaya, L. Studies of diamond and diamond-like film surfaces using XAES, AFM and wetting. Vacuum 2002, 68, 219-238. [CrossRef]

38. Werder, T.; Walther, J.H.; Jaffe, R.L.; Halicioglu, T.; Koumoutsakos, P. On the Water-Carbon Interaction for Use in Molecular Dynamics Simulations of Graphite and Carbon Nanotubes. J. Phys. Chem. B 2003, 107, 1345-1352. [CrossRef]

39. Zhou, Y.; Wang, B.; Song, X.; Li, E.; Li, G.; Zhao, S.; Yan, H. Control over the wettability of amorphous carbon films in a large range from hydrophilicity to super-hydrophobicity. Appl. Surf. Sci. 2006, 253, 2690-2694. [CrossRef]

40. Bismarck, A.; Brostow, W.; Chiu, R.; Lobland, H.E.H.; Ho, K.K. Effects of surface plasma treatment on tribology of thermoplastic polymers. Polym. Eng. Sci. 2008, 48, 1971-1976. [CrossRef]

41. Catena, A.; Guo, Q.; Kunze, M.R.; Agnello, S.; Gelardi, F.M.; Wehner, S.; Fischer, C.B. Morphological and Chemical Evolution of Gradually Deposited Diamond-Like Carbon Films on Polyethylene Terephthalate: From Subplantation Processes to Structural Reorganization by Intrinsic Stress Release Phenomena. ACS Appl. Mater. Interfaces 2016, 8, 10636-10646. [CrossRef] 
42. Tomasella, E.; Thomas, L.; Dubois, M.; Meunier, C. Structural and mechanical properties of a-C. Diam. Relat. Mater. 2004, 13, 1618-1624. [CrossRef]

43. Veres, M.; Koos, M.; Pócsik, I. IR study of the formation process of polymeric hydrogenated amorphous carbon film. Diam. Relat. Mater. 2002, 11, 1110-1114. [CrossRef]

44. Ristein, J.; Stief, R.T.; Ley, L.; Beyer, W. A comparative analysis of a-C:H by infrared spectroscopy and mass selected thermal effusion. J. Appl. Phys. 1998, 84, 3836-3847. [CrossRef]

45. Flett, M.S.C. Characteristic Frequencies of Chemical Groups in the Infrared, 1st ed.; Elsevier Publishing Co.: Amsterdam, The Netherlands; London, UK; New York, NY, USA, 1963.

46. Rao, C.N.R. Chemical Applications of Infrared Spectroscopy, 1st ed.; Academic Press: New York, NY, USA; London, UK, 1963.

47. Brüster, B.; Amozoqueño, C.; Grysan, P.; Peral, I.; Watts, B.; Raquez, J.-M.; Dubois, P.; Addiego, F. Resolving Inclusion Structure and Deformation Mechanisms in Polylactide Plasticized by Reactive Extrusion. Macromol. Mater. Eng. 2017, 302, 1700326. [CrossRef]

48. Stöhr, J. NEXAFS Spectroscopy; Springer Series in Surface Sciences 25; Springer: Berlin/Heidelberg, Germany, 1992.

49. Díaz, J.; Anders, S.; Zhou, X.; Moler, E.J.; Kellar, S.A.; Hussain, Z. Analysis of the $\pi^{*}$ and $\sigma^{*}$ bands of the x-ray absorption spectrum of amorphous carbon. Phys. Rev. B 2001, 64, 125204. [CrossRef]

50. Diaz, J.; Monteiro, O.R.; Hussain, Z. Structure of amorphous carbon from near-edge and extended x-ray absorption spectroscopy. Phys. Rev. B 2007, 76, 094201. [CrossRef]

51. Dhez, O.; Ade, H.; Urquhart, S.; Urquhart, S. Calibrated NEXAFS spectra of some common polymers. J. Electron Spectrosc. Relat. Phenom. 2003, 128, 85-96. [CrossRef]

52. Solomon, J.; Madix, R.; Stôhr, J. Orientation and absolute coverage of benzene, aniline, and phenol on Ag(110) determined by NEXAFS and XPS. Surf. Sci. 1991, 255, 12-30. [CrossRef]

53. Tai, F.C.; Lee, S.C.; Wei, C.H.; Tyan, S.L. Correlation between ID/G Ratio from Visible Raman Spectra and $\mathrm{sp}^{2} / \mathrm{sp}^{3}$ Ratio from XPS Spectra of Annealed Hydrogenated DLC Film. Mater. Trans. 2006, 47, 1847-1852. [CrossRef]

54. Dietrich, P.M.; Horlacher, T.; Girard-Lauriault, P.L.; Gross, T.; Lippitz, A.; Min, H.; Wirth, T.; Castelli, R.; Seeberger, P.H.; Unger, W.E.S. Adlayers of Dimannoside Thiols on Gold: Surface Chemical Analysis. Langmuir 2011, 27, 4808-4815. [CrossRef]

55. Schlebrowski, T.; Beucher, L.; Bazzi, H.; Hahn, B.; Wehner, S.; Fischer, C. Prediction of a-C:H layer failure on industrial relevant biopolymer polylactide acide (PLA) foils based on the $\mathrm{sp}^{2} / \mathrm{sp}^{3}$ ratio. Surf. Coat. Technol. 2019, 368, 79-87. [CrossRef] 